\title{
Complementary DNA Arrays Identify CD63 Tetraspanin and $\alpha 3$ Integrin Chain as Differentially Expressed in Low and High Metastatic Human Colon Carcinoma Cells
}

\author{
Isabelle Sordat, Charles Decraene, Timothée Silvestre, Olivier Petermann, \\ Charles Auffray, Geneviève Piétu, and Bernard Sordat
}

Experimental and Molecular Pathology Unit (IS, TS, OP, BS), Swiss Institute for Experimental Cancer Research (ISREC), Epalinges, Switzerland; and Genexpress (CD, CA, GP), Centre National de la Recherche Scientifique, Villejuif, France

\begin{abstract}
SUMMARY: Malignant tumor cell invasion is determinant for metastasis to occur. E2 and C5 colon carcinoma cells that were derived from the parental Lovo line and that differ experimentally in spontaneous metastatic ability have been monitored for gene expression by cDNA arrays. Among genes found differentially expressed, the CD63 tetraspanin, not previously recognized in colon cancer progression, and the $\alpha 3$ integrin chain were both up-regulated in low metastatic E2 cells and were analyzed for their functional role using adhesion, migration, and invasion assays. Cell surface expression of CD63 and $\alpha 3$ integrin was about 2-fold higher in E2 than in C5 cells and confocal microscopy showed that CD63 and $\alpha 3$ integrin colocalized evenly on C5 cells whereas they concentrated at elongated tips of the low-metastatic more substrate-adhesive E2 cells. Antibody-interference experiments identified laminin-5 (LN-5) as a ligand interacting with the $\alpha 3 \beta 1 / \mathrm{CD} 63$ complex. Substrate-immobilized anti-CD63 antibodies enhanced tumor cell migration and invasion and induced prominent cell surface protrusions that were repressed by the PI3-kinase LY294002 inhibitor. Our results suggest that changes in the expression of surface CD63 and $\alpha 3 \beta 1$ integrin interacting with LN-5 could affect migratory signals and the progression of the metastatic disease. (Lab Invest 2002, 82:1715-1724).
\end{abstract}

\begin{abstract}
$R$ ecent technological advances have made it possible to identify profiles of genes that are differentially expressed between either normal and transformed cells or among tumor cells analyzed at various stages of malignant progression. In colorectal tumors, quantitative gene expression patterns have been obtained using the method of serial analysis of gene expression and identifying many transcripts that were either decreased or increased in carcinomas as compared with normal colon tissue (Zhang et al, 1997). Monitoring gene expression by cDNA arrays may contribute to identifying either new classes of cancers
\end{abstract}

\section{DOI: 10.1097/01.LAB.0000044350.18215.0D}

Received July 31, 2002.

This research was funded by Swiss Science Foundation Grants 3143500.95 and 31-058955.99 (to BS), grants from Cancer Research Switzerland (KFS 567-9-1997 to BS and SKL 985-02-2000 to IS), and a grant from the Emma Muschamp Foundation. This work was supported in part by the CNRS and BIOMED Programs Consortium (BMH4-CT-972284) to CA. CD acknowledges the Fédération Française des Groupements Parkinsoniens (FFGP) and the Association pour la Recherche sur le Cancer (ARC) for fellowships. Present address of Charles Decraene and Geneviève Piétu: CEA, Service de Génomique Fonctionnelle, Evry, France. Address reprint requests to: Dr. Isabelle Sordat, Experimental and Molecular Pathology Unit, Swiss Institute for Experimental Cancer Research (ISREC), Ch. des Boveresses, 155, CH-1066 Epalinges, Switzerland. E-mail: Bernard.Sordat@isrec.unil.ch or to assigning tumors to previously known classes (Sorlie et al, 2001; Su et al, 2001).

To help in understanding pathways that mediate more specifically the ability of colorectal carcinoma cells to metastasize, we made use of cDNA clone inserts arrayed on high density nylon membrane filters to analyze two cell clones, E2 and C5, originally derived from the Lovo human colon adenocarcinoma line. When grafted to immunosuppressed newborn rats, E2 and C5 cells induce tumors that differ in basement membrane organization, grade of tumor cell differentiation, and potential to spontaneously metastasize to the lungs of recipient hosts (Remy et al, 1992). The cDNA clones were from a normalized infant brain library and the arrays used in the present study consisted of PCR products from 2208 cDNA clone inserts subjected to clone and sequence-clustering analyses (Pietu et al, 1999). Applying criteria to search for differential gene expression, 82 candidate genes were found differentially expressed between E2 and C5 colon carcinoma cells, 31 being up-regulated in the low-metastasizing E2 cells and 51 being up-regulated in the high-metastasizing C5 cells. By Northern blotting, expression profiles were verified for 10 genes, and 2 of those, the CD63 tetraspanin and the $\alpha 3$ integrin chain that were found up-regulated in the low-metastasizing E2 cells, have been selected for functional studies. 
Previous evidence suggests that levels of CD63 might be relevant to regulating human melanoma cell motility (Radford et al, 1997) and to tumor cell growth and metastasis in vivo (Hotta et al, 1991; Radford et al, 1995). The transmembrane tetraspanins can form complexes with various integrins including $\alpha 3 \beta 1$ (recently reviewed in Berditchevski, 2001; Boucheix and Rubinstein, 2001), and assembly of these complexes could modulate the function of cell surface receptors in migration and tumor invasion (Hemler et al, 1996; Sugiura and Berditchevski, 1999). In this study, we analyzed adhesion, cell shape changes, migration, and serum-stimulated invasion through Matrigel of E2 and $\mathrm{C} 5$ cells and we examined the involvement of CD63 tetraspanin and $\alpha 3$ integrin chain in these processes. Adhesion and migration of E2 and C5 cells required a functional $\alpha 3 \beta 1$ integrin, and laminin-5 (LN-5), its recognized ligand, was identified as an extracellular matrix (ECM) component interacting with the CD63/ $\alpha 3 \beta 1$ complex. Moreover, substrate-immobilized anti-CD63 antibodies induced prominent surface protrusive activity and enhanced cell migratory and invasive potential. These results indicate that the $\mathrm{CD} 63 / \alpha 3$ tetraspanin-integrin complex together with LN-5 can contribute in modulating the malignant phenotype of colon carcinoma cells.

\section{Results}

\section{Identification of Genes Differentially Expressed Between E2 and C5 Cells}

Using macroarrays containing 2208 cDNA clones to identify genes differentially expressed between E2 and C5 cells, candidate genes with at least a 1.5-fold up-regulation were selected. Applying these criteria, 82 genes were found to be differentially expressed, with 31 genes being up-regulated in E2 and 51 in C5. The complete listing of clones differentially expressed in the E2/C5 cell culture system is given in Tables 1 (genes up-regulated in E2) and 2 (genes up-regulated in C5) and can be found on a Web site at the address http://idefix.upr420.vjf.cnrs.fr/METASTASIS. A sequence similarity search revealed that 15 out of 31 clones found to be up-regulated in E2 corresponded to sequences related to human genes encoding proteins with a known function. These clones included the CD63 tetraspanin and the $\alpha 3$ integrin chain. Four clones were found homologous to genes with unknown function and 12 clones corresponded to novel genes (ESTs) that were either weakly or not homologous to sequences registered in the data bases. Thirteen out of 51 clones found to be up regulated in C5 corresponded to human genes with a known function. Twelve clones were identical to sequences of unknown function and 26 clones corresponded to novel genes with no homology to sequences in the databases.

\section{Northern Blot Analysis}

Ten genes with various levels of differential expression and including the CD63 tetraspanin and the $\alpha 3$ integrin chain were analyzed by Northern blotting (see Tables). Results were in agreement with the cDNA array data except for one single clone (yf70d05) that gave no hybridization signal. As shown in Figure 1A, an upregulation in E2 cells was confirmed for the integrin alpha3 chain (scan ratio: 1.58) and CD63 (scan ratio: 1.51).

\section{E2 and C5 Cells Express Differentially Surface CD63 Tetraspanin and $\alpha 3$ Integrin Chain Proteins}

Quantitative analyses by flow cytometry were performed to determine cell surface expression of CD63 and $\alpha 3$ integrin chain in nonpermeabilized E2 and C5 cells. As shown in Figure 1, log values of fluorescence intensities for both the $\alpha 3$ integrin chain and CD63 were approximately 2 -fold higher in E2 cells (Fig. 1, B and D) compared with C5 cells (Fig. 1, C and E), ie, 62.64 versus 36.52 for $\alpha 3$ integrin chain and 33.98 versus 18.43 for CD63, respectively. Log values for the irrelevant control fluorescein isothiocyanate (FITC)labeled antibody shown in Figure 1, B and C, were 4.7 and 4.07 , respectively.

\section{E2 Cells Adhere More Than C5 Cells to ECM Substrates}

To quantify the adhesive properties of E2 and C5 cells on ECM components, we performed a rapid adhesion assay in which cells were allowed to interact with fibronectin (FN), rat tail collagen (RTC), laminin-1 (LN1), and LN-5 coated on tissue-culture plates. As shown in Figure 2A, the low-metastatic E2 cells adhered significantly more than the high-metastatic C5 cells on the four substrates at indicated concentrations, whereas neither E2 nor C5 cells adhered to wells coated with BSA alone, used as a control.

We then determined whether cell surface $\alpha 3$ integrin and/or CD63 tetraspanin could be functionally involved in E2/C5 cell adhesion to ECM substrates. Cells were plated on FN, RTC, LN-1, or LN-5 in the presence of function blocking (P1B5 or CD49c) or nonblocking (M-KID2) anti- $\alpha 3$ integrin or anti- $\beta 1$ integrin (CD29) antibodies. As shown in Figure $2 \mathrm{~B}$, the functional anti- $\alpha 3$ integrin antibodies inhibited E2/C5 cell adhesion to LN-5 only, whereas P1B5 or CD49c did not affect cell adhesion to the other substrates tested (not shown).

In a rapid adhesion assay and in the presence of the anti-CD63 (AHN16.1) antibody, E2 and C5 cells adhered as efficiently as control cells plated without antibodies on FN, RTC, and LN-1 substrates (data not shown). In contrast, the anti-CD63 mAb significantly increased adhesion of both E2 and C5 cells when plated on LN-5 (Fig. 2B, right columns).

Because $\mathrm{LN}-5$ is a recognized ligand for $\alpha 3 \beta 1$ integrin and because twice as much $\alpha 3$ integrin chain is expressed by E2 as compared with C5 cells, we examined the level of LN-5 expressed in vitro by the two clones. Results from immunoprecipitates and Western blotting showed that conditioned medium as well as matrix assembled extracellularly by E2 and C5 cells contained similar amounts of $\mathrm{LN}-5$ (not shown). 
Table 1. List of Genes Up-Regulated in E2 Cell Line

\begin{tabular}{|c|c|c|c|c|c|c|c|c|}
\hline \multicolumn{2}{|c|}{ Clone } & \multicolumn{2}{|c|}{$\begin{array}{c}\text { Cluster (mRNA, EST, } \\
\text { eSTS) }\end{array}$} & \multicolumn{2}{|c|}{$\begin{array}{l}\text { Normalized } \\
\text { intensity }\end{array}$} & \multicolumn{2}{|c|}{ Ratio } & \multirow{2}{*}{$\begin{array}{c}\text { Description } \\
\text { Sequence similarity }\end{array}$} \\
\hline $\begin{array}{l}\text { Clone } \\
\text { name }\end{array}$ & $\begin{array}{c}\text { GenBank } \\
\text { ACC }\end{array}$ & GENX & UNIGENE & $\begin{array}{l}\text { C5 } \\
\text { INT }\end{array}$ & $\begin{array}{l}\text { E2 } \\
\text { INT }\end{array}$ & $\mathrm{E} 2 / \mathrm{C} 5$ & Northern & \\
\hline yg41e06 & R45227 & 5413 & Hs.17998 & 26.81 & 40.9 & 1.53 & ND & ESTs \\
\hline C-3FE07 & F10464 & 6825 & Hs.12272 & 7.35 & 11.66 & 1.59 & ND & Beclin 1 \\
\hline yf53b10 & R12027 & 2276 & Hs. 125273 & 5.45 & 9.85 & 1.81 & ND & ESTs \\
\hline yf61a10 & R39112 & 3960 & Hs.2288 & 2.71 & 7.32 & 2.7 & $3.10 \& 2.90$ & Visinin-like 1 \\
\hline yf78c09 & R40635 & 1664 & Hs.285255 & 1.25 & 4.12 & 3.3 & 1.62 & ESTs \\
\hline yh02g06 & R59682 & 3960 & Hs.2288 & 3.46 & 6.19 & 1.79 & ND & Visinin-like 1 \\
\hline yg02d04 & R18404 & 216 & Hs.132875 & 3.55 & 5.62 & 1.58 & ND & Phosphatidylinositol glycan, class S \\
\hline yc87b06 & T75087 & 5479 & Hs.23767 & 2.38 & 4.59 & 1.92 & ND & $\begin{array}{l}\text { Homo sapiens cDNA FLJ12666 fis, clone } \\
\text { NT2RM4002256 }\end{array}$ \\
\hline yg27a08 & R43968 & 4127 & Hs169921 & 2.05 & 4.03 & 1.96 & ND & $\begin{array}{c}\text { General transcription factor II, i, } \\
\text { pseudogene } 1\end{array}$ \\
\hline yh13e12 & $\mathrm{R} 60517$ & 3960 & Hs.2288 & 3.05 & 4.69 & 1.54 & ND & Visinin-like 1 \\
\hline ym04e05 & H10556 & 3960 & Hs.2288 & 1.64 & 3.45 & 2.11 & 1.87 & Visinin-like 1 \\
\hline yg36f04 & $\mathrm{R} 24580$ & 5214 & ND & 2.34 & 3.7 & 1.58 & ND & ND \\
\hline yd09f12 & R39085 & 2991 & Hs.284311 & 1.34 & 2.54 & 1.89 & ND & Homo sapiens clone 25038 mRNA sequence \\
\hline yg16d07 & R43459 & 1087 & Hs. 87125 & 1.44 & 2.43 & 1.68 & ND & EH-domain containing 3 \\
\hline yf92c12 & R42531 & 92 & Hs.129673 & 1.55 & 2.47 & 1.59 & ND & $\begin{array}{l}\text { Eukaryotic translation initiation factor } 4 \mathrm{~A} \\
(\mathrm{elF}-4 \mathrm{~A}) \text { isoform } 1\end{array}$ \\
\hline$y f 48 c 10$ & R12797 & 9043 & Hs.10842 & 1.26 & 2.22 & 1.76 & ND & RAN, member RAS oncogene family \\
\hline yg91d11 & R56572 & 12808 & ND & 0.78 & 1.78 & 2.29 & ND & ESTs \\
\hline yg29a08 & R44529 & 5096 & Hs. 155433 & 0.76 & 1.76 & 2.32 & ND & $\begin{array}{l}\text { ATP synthase, } \mathrm{H}+\text { transporting, } \\
\text { mitochondrial } \mathrm{F} 1 \text { complex, gamma } \\
\text { polypeptide } 1\end{array}$ \\
\hline yg42a01 & R45385 & 1907 & ND & 1.11 & 2.03 & 1.82 & ND & KIAA1765 protein \\
\hline yg48g03 & R45998 & 753 & Hs.76294 & 1.29 & 2.14 & 1.66 & 1.51 & CD63 antigen (melanoma 1 antigen) \\
\hline yf57d07 & R20533 & 12763 & Hs.109706 & 0.95 & 1.84 & 1.93 & ND & HN1 protein \\
\hline yg64g08 & R51110 & 115205 & Hs.77306 & 1.33 & 2.07 & 1.56 & ND & $\begin{array}{l}\text { Survival of motor neuron } 2 \text {, centromeric } \\
\text { solute carrier family } 7 \text {, (cationic amino acid } \\
\text { transporter, } y+\text { system) member } 11\end{array}$ \\
\hline C-3JG01 & F10774 & 10804 & Hs.6682 & 0.89 & 1.71 & 1.93 & ND & \\
\hline yc94e07 & T77478 & 3740 & Hs.182643 & 0.89 & 1.66 & 1.87 & ND & $\begin{array}{l}\text { Transcription elongation factor B (SIII), } \\
\text { polypeptide 1-like }\end{array}$ \\
\hline $\mathrm{y} 178 \mathrm{~g} 02$ & H06573 & 9470 & Hs.265829 & 0.19 & 0.85 & 4.42 & 1.58 & $\begin{array}{c}\text { Integrin alpha-3 (antigen CD49C, alpha } 3 \\
\text { subunit of VLA-3 receptor) }\end{array}$ \\
\hline yg16d03 & R43455 & 200622 & Hs. 85100 & 0.64 & 1.42 & 2.23 & ND & WD repeat domain 1 \\
\hline C-3ЕH06 & F10419 & 10607 & Hs. 226275 & 0.61 & 1.33 & 2.18 & ND & KIAA0683 gene product \\
\hline C-3DE04 & F10332 & 10557 & Hs.180372 & 0.95 & 1.56 & 1.64 & ND & $\begin{array}{l}\text { Homo sapiens cDNA FLJ20750 fis, clone } \\
\text { HEP051174 }\end{array}$ \\
\hline yf94h04 & R14951 & 1424 & ND & 0.3 & 0.96 & 3.22 & ND & \\
\hline yf52g03 & R36889 & 319 & Hs.171807 & 0.97 & 1.51 & 1.56 & ND & $\begin{array}{l}\text { Homo sapiens cDNA: FLJ23260 fis, clone } \\
\text { COL05804, highly similar to HSU90911 } \\
\text { human clone } 23652 \text { mRNA sequence }\end{array}$ \\
\hline yh10g09 & R61277 & 4858 & Hs. 8073 & 0.56 & 1.05 & 1.87 & ND & Septin 3 \\
\hline
\end{tabular}

These results suggest that both $\alpha 3$ integrin chain and CD63 tetraspanin can interact with E2 and C5 cell adhesion to $\mathrm{LN}-5$.

\section{CD63 Tetraspanin, $\alpha 3$ Integrin, and LN-5 Participate in Migration of E2 and C5 Cells}

We tested E2 and C5 cells in a wound-closure assay that is considered to be an in vitro model for epithelial cell migration during wound repair and invasion. Lin- ear scrape wounding of confluent E2 or C5 cells was performed and cultures were allowed to undergo healing in the presence of serum for 17 and 24 hours. To investigate a possible role of $\alpha 3$ integrin, $\mathrm{LN}-5$, and CD63 tetraspanin on wound healing, we assessed the effect of antibodies P1B5 (anti- $\alpha 3$ integrin chain), BM165 (anti-LN-5 $\alpha 3$ subunit), and AHN16.1 (antiCD63 tetraspanin) as compared with wounds in E2 and $\mathrm{C} 5$ control cell populations incubated without antibodies. As quantitated by multiple measurements 
Table 2. List of Genes Up-Regulated in C5 Cell Line

\begin{tabular}{|c|c|c|c|c|c|c|c|c|}
\hline \multicolumn{2}{|c|}{ Clone } & \multicolumn{2}{|c|}{$\begin{array}{c}\text { Cluster (mRNA, EST, } \\
\text { eSTS) }\end{array}$} & \multicolumn{2}{|c|}{ Normalized intensity } & \multicolumn{2}{|c|}{ Ratio } & \multirow{2}{*}{$\frac{\text { Description }}{\text { Sequence similarity }}$} \\
\hline $\begin{array}{l}\text { Clone } \\
\text { name }\end{array}$ & $\begin{array}{l}\text { GenBank } \\
\text { Acc }\end{array}$ & GENX & UNIGENE & C5 INT & E2 INT & C5/E2 & Northern & \\
\hline yg53c11 & R62454 & 5862 & Hs. 240257 & 8.21 & 4.02 & 2.04 & 1.49 & ESTs \\
\hline yg67g12 & R49555 & 5193 & Hs.26270 & 8.44 & 4.84 & 1.75 & ND & $\begin{array}{c}\text { Homo sapiens cDNA FLJ11588 fis, clone } \\
\text { HEMBA } 1003729\end{array}$ \\
\hline yg51a11 & R46587 & 201606 & Hs.278614 & 8.06 & 5.23 & 1.54 & ND & Protease, serine, 15 \\
\hline C3DB10 & F10309 & 10541 & Hs.267194 & 6.55 & 3.98 & 1.65 & ND & Hypothetical protein MGC2488 \\
\hline yg84e05 & R53555 & 4189 & Hs.15386 & 6.41 & 3.93 & 1.63 & ND & ESTs \\
\hline yg04d11 & R41927 & 326 & Hs.21757 & 6.65 & 4.43 & 1.5 & ND & ESTs \\
\hline yg74c01 & R54229 & 307 & ND & 6.31 & 4.01 & 1.57 & ND & \\
\hline yl99e10 & $\mathrm{H} 10661$ & 2383 & Hs.192124 & 6.12 & 3.77 & 1.62 & ND & ESTs \\
\hline yg17a11 & R43271 & 2431 & Hs.374319 & 6.12 & 4.05 & 1.51 & ND & Hypothetical protein FLJ10509 \\
\hline yf90c05 & R42103 & 2186 & Hs.75627 & 5.56 & 3.66 & 1.52 & ND & CD14 antigen \\
\hline yf70d05 & R12919 & 4318 & Hs.6189 & 4.99 & 2.95 & 1.69 & 0 & KIAA1467 protein \\
\hline yd03a01 & T80207 & 1554 & Hs. 273230 & 5.27 & 3.5 & 1.51 & ND & Hypothetical proteinFJL10830 \\
\hline yg02f03 & R18419 & 2758 & ND & 4.51 & 2.63 & 1.72 & ND & \\
\hline ус94а07 & T77388 & 10872 & Hs.170226 & 4.55 & 2.72 & 1.68 & ND & Homo sapiens clone 23579 mRNA sequence \\
\hline yf68d06 & R40025 & 5444 & Hs.106551 & 2.97 & 1.3 & 2.29 & ND & ESTs \\
\hline yf49g02 & R17697 & 3043 & Hs.140963 & 3.22 & 1.86 & 1.73 & ND & ESTs \\
\hline yf48h04 & R12182 & 2046 & Hs.6349 & 2.75 & 1.31 & 2.1 & ND & Hypothetical gene BC008967 \\
\hline yl89e01 & H08734 & 5054 & Hs.79191 & 1.94 & 0.58 & 3.33 & ND & ESTS \\
\hline yl96g09 & H09060 & 11047 & ND & 2.01 & 0.64 & 3.12 & ND & \\
\hline yg10e09 & R43254 & 3663 & Hs.174287 & 3.14 & 1.91 & 1.64 & ND & EST \\
\hline yf55h04 & R12357 & 664 & ND & 2.93 & 1.87 & 1.57 & ND & \\
\hline yg52d11 & $\mathrm{R} 62429$ & 2543 & Hs.288785 & 2.15 & 0.86 & 2.51 & 2.2 & "Homo sapiens mRNA; cDNA DKFZp5661043" \\
\hline yh01e05 & $\mathrm{R} 66445$ & 1842 & Hs.22003 & 2.64 & 1.46 & 1.81 & ND & $\begin{array}{c}\text { Solute carrier family } 6 \text { (neurotransmitter } \\
\text { transporter, GABA), member } 1\end{array}$ \\
\hline yg75d03 & R54519 & 256 & Hs. 184640 & 2.6 & 1.48 & 1.76 & ND & Chromosome 11 open reading frame 9 \\
\hline yg79c05 & R52305 & 20313 & Hs.200596 & 1.79 & 0.63 & 2.82 & ND & KIAA0547 gene product \\
\hline yf99e07 & R42173 & 3807 & Hs.118778 & 1.86 & 0.79 & 2.35 & 3.47 & $\begin{array}{l}\text { KDEL (Lys-Asp-Glu-Leu) endoplasmic } \\
\text { reticulum protein retention receptor } 2 \\
\text { Human DNA sequence from clone } 167 \text { A19 on } \\
\text { chromosome } 1 \text { p32.1-33. Contains three } \\
\text { genes for novel proteins, the DIO1 gene for } \\
\text { type I iodothyronine deiodinase (EC } 3.8 .1 .4, \\
\text { TXDI1, ITDI1) and an HNRNP }\end{array}$ \\
\hline yf49g10 & R11887 & 2696 & Hs.40094 & 2.14 & 1.16 & 1.85 & ND & $\begin{array}{l}\text { A3 (heterogenous nuclear ribonucleoprotein } \\
\text { A3, FBRNP) pseudogene. Contains ESTs, } \\
\text { STSs, GSSs, genomic marker D1S2661, ca } \\
\text { and ct repeat polymorphisms and three } \\
\text { putative CpG islands }\end{array}$ \\
\hline yg99c03 & R52676 & 2705 & Hs.12314 & 2.06 & 1.06 & 1.95 & ND & $\begin{array}{c}\text { Homo sapiens mRNA cDNA DKFZp586C1019 } \\
\text { (from clone DKFZp586C1019) }\end{array}$ \\
\hline yf63c07 & R39877 & 9568 & Hs.167405 & 2.04 & 1.06 & 1.92 & ND & ESTs \\
\hline yg90g07 & R56334 & 2762 & Hs.234216 & 1.99 & 1.03 & 1.92 & ND & Human 40871 mRNA partial sequence \\
\hline yc88e11 & R39170 & 10572 & Hs.12332 & 2.08 & 1.18 & 1.75 & ND & ESTs \\
\hline yg67a09 & R49532 & 10826 & Hs.25027 & 1.87 & 0.99 & 1.89 & ND & ESTs \\
\hline yl71g02 & $\mathrm{H} 13029$ & 694 & Hs.12942 & 2.1 & 1.4 & 1.51 & ND & Vesicle trafficking protein \\
\hline yg97h02 & $\mathrm{R} 59284$ & 1734 & ND & 1.42 & 0.54 & 2.64 & 2.89 & \\
\hline yg51a12 & R46588 & 18636 & Hs.172089 & 1.99 & 1.33 & 1.5 & ND & $\begin{array}{l}\text { Pro-oncosis receptor inducing membrane } \\
\text { injury gene }\end{array}$ \\
\hline yf72a03 & R40479 & 115273 & Hs.244426 & 1.88 & 1.2 & 1.57 & ND & $\begin{array}{l}\text { Solute carrier family } 6 \text { (neurotransmitter } \\
\text { transporter, creatine), member } 8\end{array}$ \\
\hline yg91b01 & R40771 & 2195 & HS.21631 & 1.47 & 0.66 & 2.24 & ND & EST \\
\hline yg77d10 & R51798 & 71 & ND & 1.62 & 0.88 & 1.85 & ND & \\
\hline yf91h12 & R42519 & 2582 & Hs.16577 & 1.44 & 0.7 & 2.07 & ND & F-box only protein 3 \\
\hline yf77d12 & R14199 & 4153 & Hs.76666 & 1.57 & 0.91 & 1.71 & ND & C9orf10 protein \\
\hline yg83b05 & R53938 & 20476 & ND & 1.51 & 0.92 & 1.63 & ND & \\
\hline $\mathrm{C} 05 \mathrm{C} 01$ & F01511 & 2515 & Hs.7840 & 1.53 & 0.97 & 1.59 & ND & Calcineurin binding protein cabin 1 \\
\hline yg46d02 & R45308 & 3081 & Hs.18995 & 1.12 & 0.47 & 2.37 & ND & KIAA1304 protein \\
\hline yg17e10 & R18915 & 4356 & Hs.62112 & 1.49 & 0.96 & 1.55 & ND & Zinc finger protein 207 \\
\hline yf $49 c 08$ & R17677 & 115202 & Hs.73818 & 1.38 & 0.82 & 1.69 & ND & Hypothetical protein DKFZp564A176 \\
\hline yg19c11 & $\mathrm{R} 43697$ & 1068 & Hs.226581 & 1.24 & 0.7 & 1.77 & ND & Cytochrome $c$ oxidase subunit 15 \\
\hline yc94d11 & T77428 & 2212 & Hs.289733 & ND & ND & ND & ND & Hypothetical protein DKFZp7610031.1 \\
\hline yg73c09 & $\mathrm{R} 51740$ & 203841 & Hs.288959 & 1.22 & 0.74 & 1.66 & ND & $\begin{array}{l}\text { Homo sapiens CDNA: FLJ20920 fis, clone } \\
\text { ADSE00877 }\end{array}$ \\
\hline yc90c11 & R39267 & 201124 & Hs.106330 & 0.83 & 0.28 & 2.92 & ND & ESTs \\
\hline С $3 \mathrm{HAO3}$ & F10565 & 10691 & Hs.268742 & 0.98 & 0.42 & 2.3 & ND & ESTs \\
\hline yf55e03 & R12333 & 2958 & Hs.288778 & 1.16 & 0.71 & 1.63 & ND & LAT1-3TM protein \\
\hline
\end{tabular}

of the width of the wound space, as shown in Figure $3 \mathrm{~A}$ for $\mathrm{E} 2$ cells, antibodies to the $\alpha 3 \mathrm{LN}-5$ subunit and to the $\alpha 3$ integrin inhibited wound healing, with approximately 67 and $50 \%$, respectively, of initial injured width at 24 hours (C5 cells gave similar results; not shown). In contrast, primary coating alone or adding the AHN16.1 anti-CD63 antibody to the medium of precoated and wounded cultures enhanced healing of the denuded E2 cell area at the wound edge up to 46 and $36 \%$ at 17 and 24 hours, respectively, reaching 


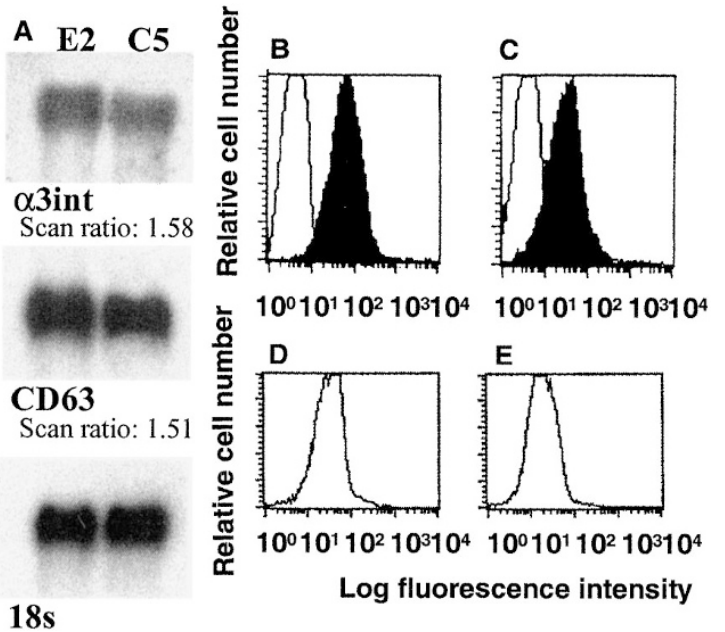

Figure 1.

A, Northern blot analysis of $\alpha 3$ integrin chain and CD63 genes. Lanes E2 and C5 correspond to low- and high-metastatic colorectal carcinoma clone RNAs, respectively. Filters have been stripped and hybridized with a $18 \mathrm{~S}$ probe. B-E, Surface expression of $\alpha 3(\mathrm{~A}, \mathrm{~B})$ integrin chain and CD63 (C, D) on E2 (B and $\mathrm{D})$ and $\mathrm{C} 5$ (C and $\mathrm{E}$ ) nonpermeabilized cells stained with P1B5 mAb against $\alpha 3$ integrin and AHN16.1/46-4-5 FITC against CD63 or irrelevant control antibody and examined by flow cytometry.

complete healing (Fig. 3B). Adding the anti-LN-5 $\alpha 3$ subunit BM165 antibody inhibited the anti-CD63induced healing-enhancing effect by about 65\% (Fig. 3C). This inhibition was even more pronounced in the presence of the anti- $\alpha 3$ integrin P1B5 antibody (up to 80\%; see Fig. 3D). In both E2 and C5 cells, coating with the anti-CD63 mAb induced cell shape changes more easily recognized in cells located at the advancing wound edge (described below). These results indicate that the enhanced ability of E2 and C5 colon carcinoma cells to migrate appears to result from the interactions of LN-5 with both cell surface $\alpha 3$ integrin and the CD63 tetraspanin.

\section{A Role for the CD63 Tetraspanin in Invasive Migration}

To examine whether the anti-CD63 mAb could equally modulate E2/C5 cell invasive capacity, we performed a series of experiments using the twocompartment invasion chamber assay. When seeded on a Matrigel-conditioned polycarbonate filter, C5 cells constitutively invade up to 1.6-fold more than E2 cells in a 18- to 24-hour assay. Interestingly, the mAb to CD63 admixed together with Matrigel increased invasiveness up to 1.5-fold for both E2 and C5 cells (Fig. 4). Moreover, the presence of the anti-CD63 antibodies in the medium of the upper compartment and not within the Matrigel-conditioned filter did not significantly alter the extent of invasive migration.

\section{Anti-CD63 Antibodies Induce E2/C5 Cell Protrusive Activity}

Using fixed and permeabilized E2/C5 cells, cultured in plannar conditions on plastic substrate, we examined the distribution of CD63 tetraspanin and $\alpha 3$
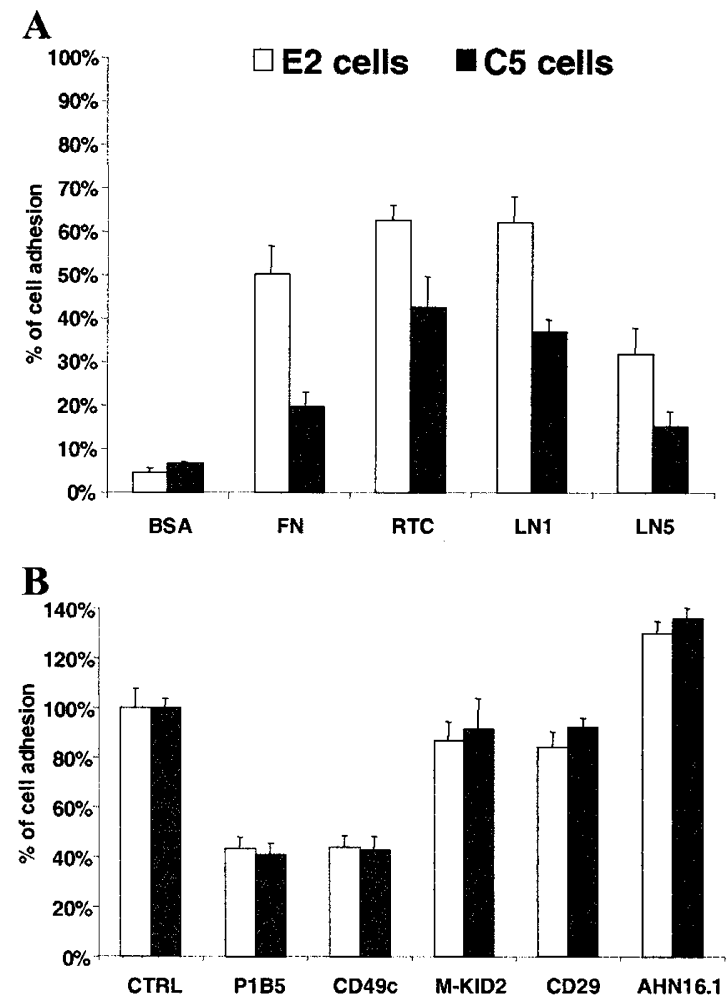

Figure 2.

A, Adhesion of E2 and C5 cells to BSA, FN, RTC, LN-1, and LN- 5 substrates. Ninety-six-well plates were coated with BSA $1 \%, 50 \mu \mathrm{g} / \mathrm{ml}$ FN, $50 \mu \mathrm{g} / \mathrm{ml}$ RTC, $50 \mu \mathrm{g} / \mathrm{ml} \mathrm{LN}-1$, or $1 \mu \mathrm{g} / \mathrm{ml} \mathrm{LN}-5$ and blocked with $1 \%$ BSA. Cells were seeded at $5 \times 10^{4}$ cells/well. A 45-minute adhesion assay was performed as described in "Materials and Methods." Results are expressed as percentage of cell adhesion $\pm S D$. B, Effects of anti- $\alpha 3$-integrin and anti-CD63 antibodies on E2 and $\mathrm{C} 5$ cell adhesion to LN-5. Multiwell plates were coated with LN-5 at 1 $\mu \mathrm{g} / \mathrm{ml}$. After saturation with $1 \% \mathrm{BSA}$, the cells, preincubated with $50 \mu \mathrm{g} / \mathrm{ml}$ P1B5, $50 \mu \mathrm{g} / \mathrm{ml} \mathrm{CD49c} \mathrm{(both} \alpha 3$ integrin function-blocking antibodies), 50 $\mu \mathrm{g} / \mathrm{ml} \mathrm{M-KID2} \mathrm{(an} \alpha 3$ integrin non-function-blocking antibody), and $25 \mu \mathrm{g} / \mathrm{ml}$ CD29 against $\beta 1$ integrin chain or $25 \mu \mathrm{g} / \mathrm{ml}$ AHN16.1 (anti-CD63), were seeded. After 45 minutes, adhesion was determined as in A. The results are expressed as a percentage of the control without antibodies. SD values indicated in the graph were determined from data derived from three experiments.

integrin chain by dual immunostaining and confocal scanning microscopy. We found that both were uniquely concentrated at elongation tips of E2 cells (Fig. 5C, merge, arrows) whereas $\alpha 3$ integrin signal alone produced a characteristic overall cell surface association (Fig. 5B) and CD63 tetraspanin a major cytoplasmic vesicular localization as well as focal membrane reactivity (Fig. 5A). In contrast, in C5 cells that grow as single or clustered rounded cells loosely attached to the substrate, colocalization was more evenly distributed on the cell surface (Fig. $5 \mathrm{~F}$, merge, arrow) and there was no distinct focal concentration of CD63 (Fig. 5D) and $\alpha 3$ integrin chain (Fig. 5E). We then examined the effect of substrate-immobilized AHN16.1 or TS63 anti-CD63 mAbs on the morphology of E2/C5 cells plated in plannar conditions. Anti-CD63 coating induced the formation of long and numerous cytoplasmic protrusions during the first 24 hours and starting around 2 to 4 hours after plating (Fig. 6A, arrow). 


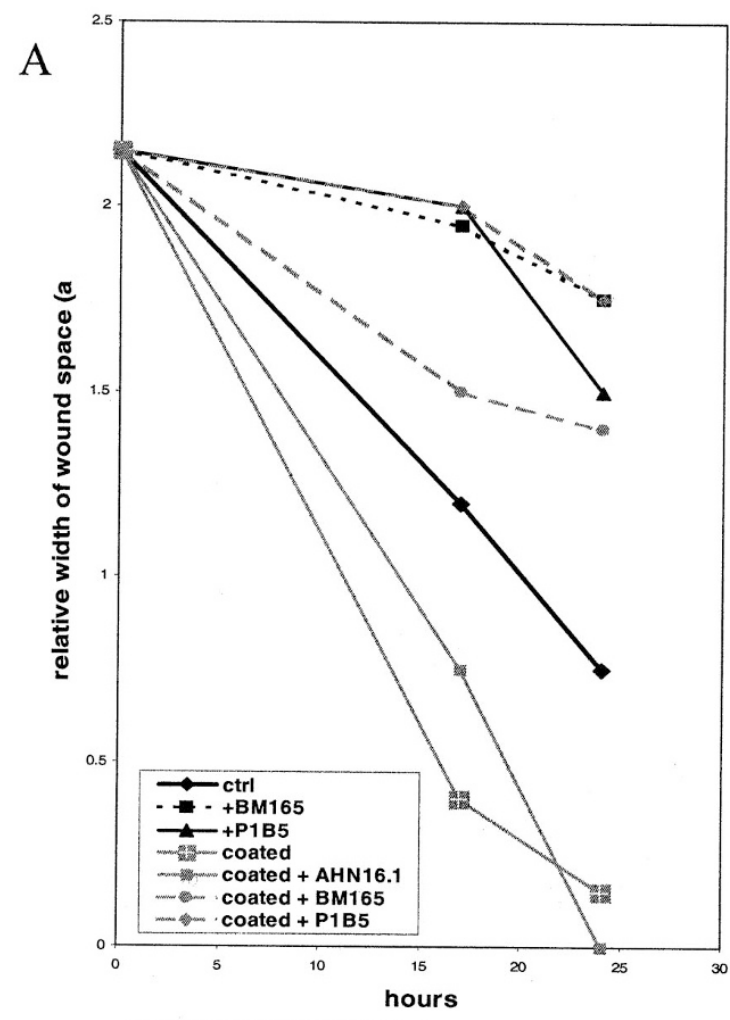

B

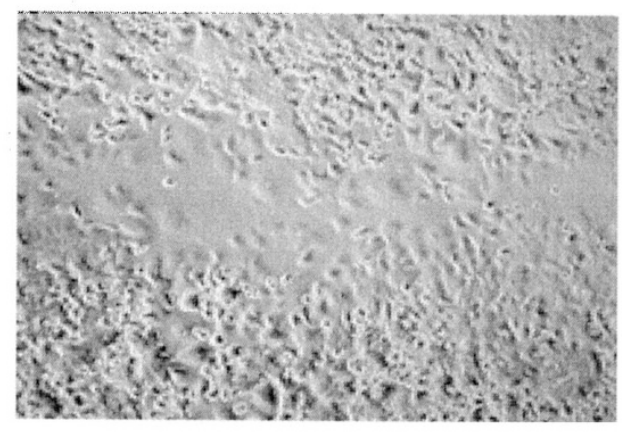

$\mathrm{C}$

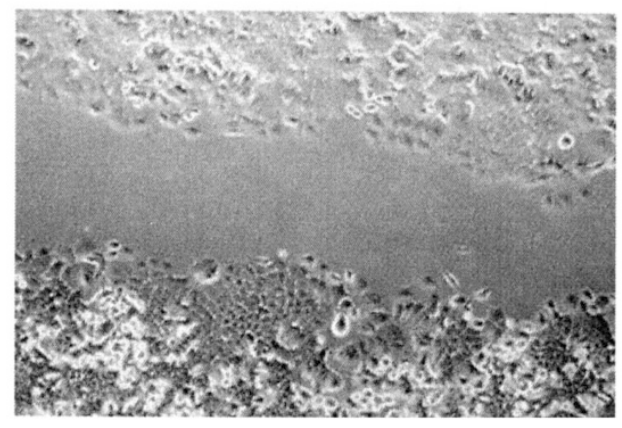

$\mathrm{D}$

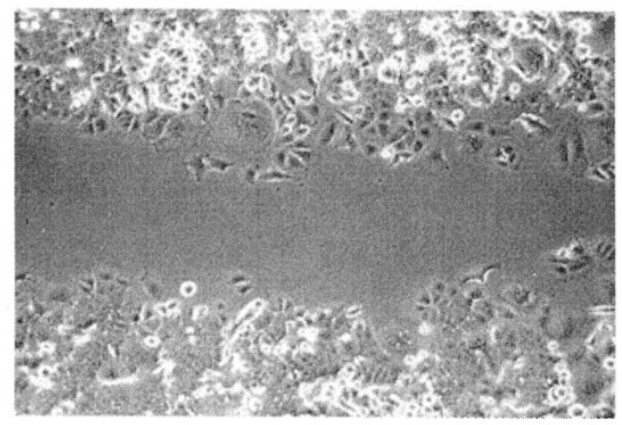

Over $50 \%$ of E2 cells and over $20 \%$ of C5 cells showed cell surface extensions that often exceeded the cell body diameter and gave the cells a stellate morphology. Preliminary results using time-lapse microscopy indicate that anti-CD63-mediated cell protrusive activity in plannar culture conditions is a highly dynamic process during which protrusions undergo rapid and repeated cycles of extension and retraction (our unpublished results). No similar basal protrusive activity could be detected in the absence of anti-CD63 coating and no significant morphological changes were observed when E2 or C5 cells were plated on P1B5 or BM165 mAb-coated surfaces. Moreover, coincubation of cells with the anti-LN-5 $\alpha 3$ subunit antibody (BM165) (6B) or with the anti- $\alpha 3$ integrin chain (P1B5) (Fig. 6C) did not significantly alter the extent of the anti-CD63 antibody-induced cell protrusions. Similar changes in breast carcinoma cells were reported to involve various classes of signaling enzymes, and a specific inhibitor of phosphoinositide 3-kinase (PI3K), LY294002, could inhibit morphogenetic changes triggered by antitetraspanin antibodies (Sugiura and Berditchevski, 1999). Indeed, LY294002 (10 $\mu \mathrm{M})$ repressed the protrusive response of E2/C5 colon carcinoma cells exposed to coated anti-CD63 antibodies (Fig. 6D for E2 cells).

\section{Discussion}

Our results using cDNA arrays, Northern blotting, and flow cytometry analyses show that expression of both CD63 and $\alpha 3$ integrin chain mRNAs and surface proteins is 2-fold higher in the low-E2 than in the high-metastatic C5 human colon carcinoma cells. In our study, differentially expressed genes represented $3.7 \%$ of the total genes in the array, in accordance with the 1 to $5 \%$ differentially expressed genes found in gastrointestinal tumors (Zhang et al, 1997). No differential expression ratio was greater than four (average around 2-fold), and we attribute this result to the close genetic match of the cultured E2/C5 cells that are derived from the unique parental Lovo line. With regard to the use of the E2/C5 cell lines, a previous study reported that many of the differences in gene expression that distinguish normal from tumor cells in vivo may persist during in vitro growth maintenance (Zhang et al, 1997). Indeed, in a large panel of human tumor-derived cell lines, including colon carcinoma, a consistent relationship has been found be-

\footnotetext{
Figure 3.

A, Quantitative analysis of the wound closure assay. Linear scrape wounds were made in subconfluent E2 cell monolayers, and cultures in the presence of $5 \%$ FBS were allowed to heal for 17 and 24 hours in the presence of antibodies that inhibit the function of $\alpha 3$ integrin (P1B5) or the $\alpha 3$ LN-5 subunit (BM165). Wounded cultures grown on anti-CD63 (AHN16.1)-coated surface healed readily after 24 hours in the absence of antibody, whereas P1B5 and BM165 mAbs inhibited markedly the enhancement of wound closure. The average extent of closure was quantitated by multiple measurements of the width of wound space for each case at 0,17 , and 24 hours. Five measurements in three separate trials were made. B, C, and D, Representative examples of wounds at 24 hours after initial scrape and where E2 cells were exposed to coated and medium-added anti-CD63 mAb (B) or in the presence of a function-blocking anti- $\alpha 3$ integrin (C) or of an anti-LN-5 $\alpha 3$ subunit (D) antibody.
} 


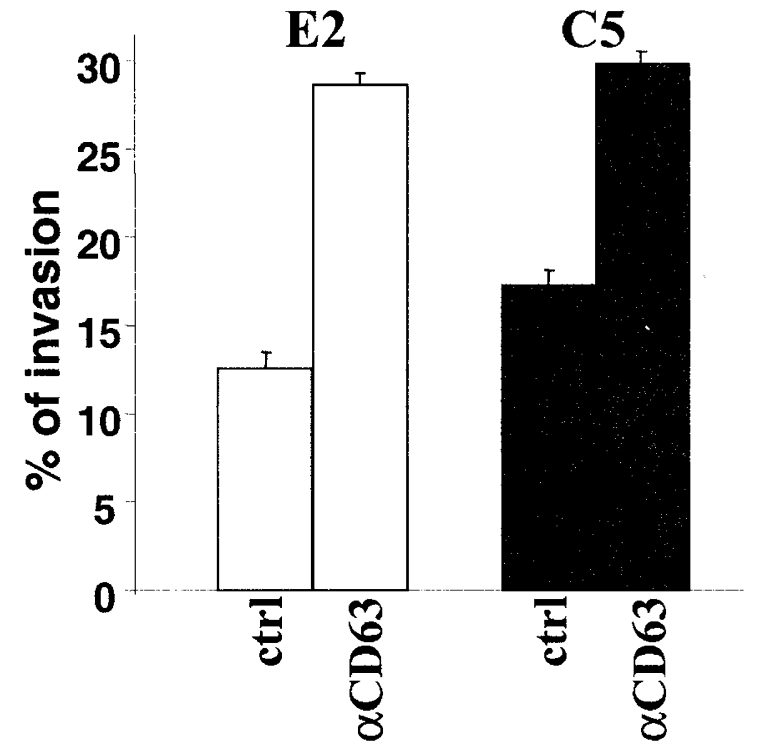

Figure 4.

Invasion chamber assay. E2 and C5 cells were allowed to migrate through an $8-\mu \mathrm{m}$ pore-size polycarbonate filter conditioned with Matrigel. Assays were performed for 24 hours with or without the anti-CD63 mAb $(25 \mu \mathrm{g} / \mathrm{ml})$ admixed to Matrigel. Results expressed as means \pm sD. tween the patterns of gene expression in vitro and the tissue of origin (Ross et al, 2000).

E2 and C5 clones were originally reported to induce colon carcinoma xenografts that differed in basement membrane organization, cellular differentiation grade, and metastatic ability, C5 cells being significantly more prone than E2 cells to induce spontaneous lung metastases in immune-deficient hosts (Remy et al, 1992). We here identified the CD63 tetraspanin, not previously known to be implicated in colon cancer progression, and the $\alpha 3$ integrin chain as two components whose expression could modulate metastatic ability. Several members of the tetraspanin family, including CD63, can interact with the $\alpha 3 \beta 1$ integrin (Berditchevski et al, 1995), and complexes of tetraspanins with integrins can modulate the expression of malignant properties of tumor cells (reviewed in Boucheix et al, 2001; Hemler et al, 1996). While CD63 was originally reported as strongly expressed at early stages of melanoma, then down-regulated at advanced stages (Hotta et al, 1988), its ectopic expression in human melanoma cells repressed their metastatic potential in nude mice, indicating a suppressor role that could act to limit tumor invasion and progression (Radford et al, 1995).
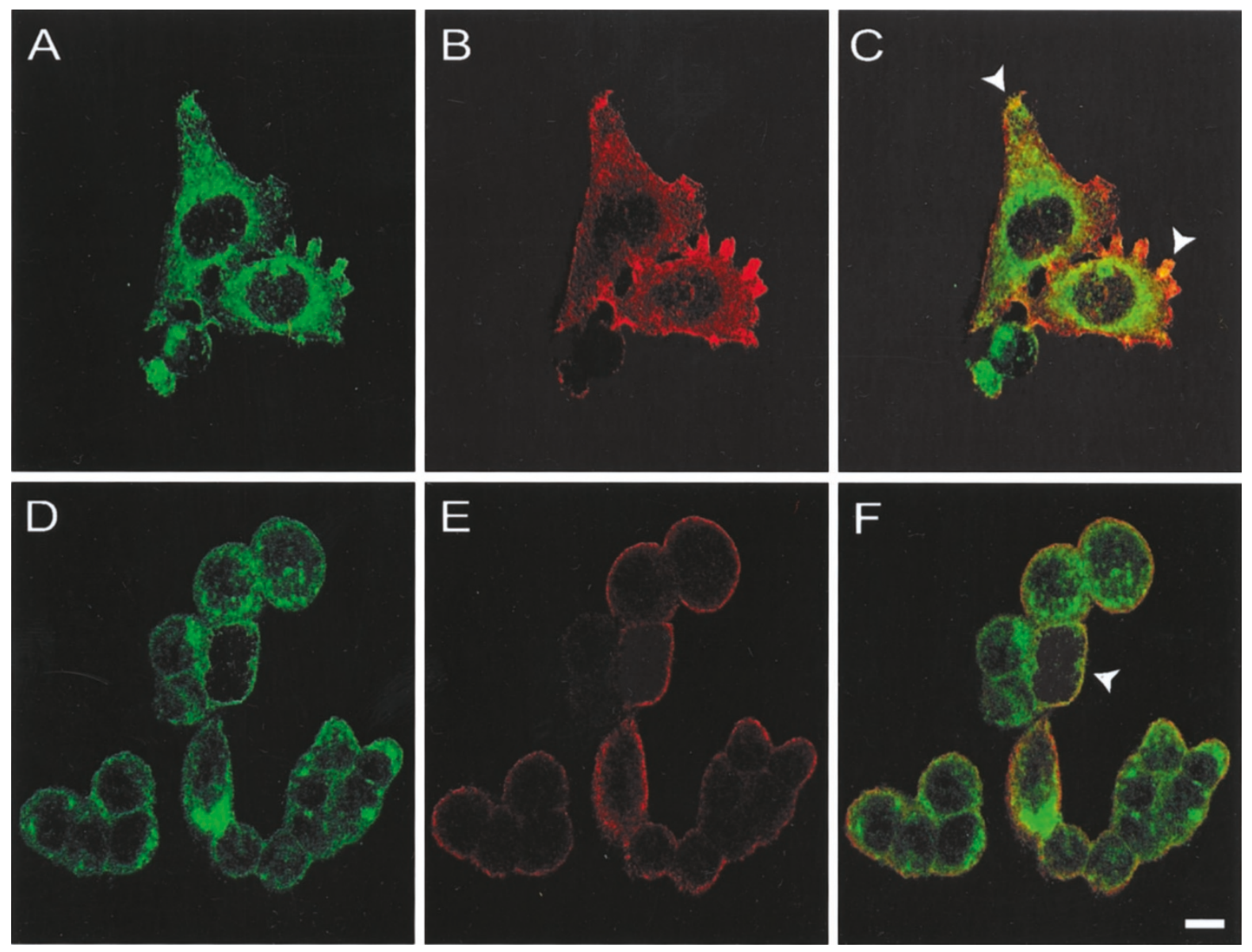

Figure 5.

Cellular localization of $\alpha 3$ integrin chain (B and E) and CD63 tetraspanin (A and D) in C5 (D, E, F) and E2 (A, B, C) colon carcinoma cells. Dual immunostaining was performed as described in "Materials and Methods." $\mathrm{C}$ and F, Merged confocal pictures for E2 and C5 cells, respectively. Arrows indicate colocalization of $\alpha 3$ integrin and CD63 tetraspanin concentrated at the tips of elongated E2 cells $(\mathrm{C})$ and more evenly on C5 cell surface $(\mathrm{F})$. Bar $=10 \mu \mathrm{m}$. 
The present study shows that low-metastatic E2 cells are more adherent and substrate-anchored than C5 cells, as tested on fibronectin, collagen, and laminin-1 and -5 . As expected, adhesion to LN-5 only could be inhibited by function-blocking antibodies against the $\alpha 3$ integrin receptor. Both E2 and C5 cells express similar amounts of $\mathrm{LN}-5$, and $\alpha 3 \beta 1$ integrin is known to associate with CD63 tetraspanin (Berditchevski et al, 1995). Interestingly, precoated antiCD63 antibodies enhanced cell adhesion and spreading when $\alpha 3$ integrin was engaged with LN-5 but not when the other ligands were used. This is in contrast with other studies in which antibodies to another tetraspanin, the CD151 that stably associates with $\alpha 3 \beta 1$ integrin, could functionally inhibit neurite outgrowth but had minimal effect on $\alpha 3$ or $\alpha 6$ integrinmediated cell adhesion (Stipp and Hemler, 2000).

The fact that CD151 associates positively whereas CD63 associates negatively with the ability of malignant cells to metastasize may be relevant to signaling through unique tetraspanin-integrin complexes (Hemler, 2001). We noticed that precoating anti-CD63 antibodies is required for enhancing tumor cell migration in both the wound closure assay and the invasive migration assay. The latter experimental condition may be particularly relevant because enhanced invasion was not induced with soluble anti-CD63 antibodies added in the upper compartment of the chamber and not admixed within Matrigel $^{\mathrm{R}}$. We suggest that antibodyimmobilized CD63 may affect the physical strength of the integrin-tetraspanin complexes at and through the cell matrix contact sites to facilitate or activate signal transduction. Both anti-CD63 antibody-induced enhanced migration and invasion were repressed by anti-LN-5 or/and $\alpha 3$ integrin antibodies, supporting again a functional role of the CD63/ $\alpha 3$ complex depending on the engagement of CD63-associated $\alpha 3$ integrin in LN-5 ligand binding. As shown by flow cytometry, E2 cells express about 2-fold more surface CD63 and $\alpha 3$ integrin than C5 cells. Confocal microscopy showed that E2 and C5 cells differ in surface codistribution of CD63 and $\alpha 3$ integrin, a pattern compatible with a greater capacity for substrate anchorage of the low-metastatic E2 cells as compared with C5 cells. A more even surface codistribution of $\mathrm{CD} 63 / \alpha 3$ integrin complexes in $\mathrm{C} 5$ cells could correspond to higher cellsubstrate anchorage independence and migratory signaling. Tetraspanin-integrin associations have been found in focal complexes of lamellipodial and filopodial extensions of migrating cells but were reported to be excluded from classical focal adhesions (Berditchevski and Odintsova, 1999).

It remains to be investigated whether, in E2/C5 cells, antibody-mediated ligation of CD63 affects tyrosine phosphorylation of focal adhesion kinase (FAK) to modulate integrin function (Berditchevski and Odintsova, 1999). Cell protrusions are considered as sites where cell-substrate contacts for traction are formed. Ligation of CD63 with substrateimmobilized antibodies triggered a prominent protrusive cellular activity together with enhanced migration and invasion. Our results suggest that such CD63/ $\alpha 3$ integrin complexes could be involved in weak and temporary adhesion events critical for modulating tumor cell attachment to matrix ligands including Ln-5. Repression of cellular protrusive activity by the LY294002 inhibitor indicates a functional link between mAb-induced CD63 ligation and the PI3K/AKT signaling pathway (Sugiura and Berditchevski, 1999; Testa and Bellacosa, 2001). PI3K is known to be involved in the dynamics of the actin cytoskeleton (Schmidt and Hall, 1998), and a recent study reported that $\mathrm{PI} 3 \mathrm{~K}$ can have a stimulatory role in chemotactic migration of keratinocytes on LN-5 as driven by the $\alpha 3 \beta 1$ integrin (Hintermann et al, 2001). Furthermore, experiments carried out with breast carcinoma cells showed that PI3Kdependent signaling can also contribute to the induction of the matrix-degrading metalloproteinase MMP-2 triggered by $\alpha 3 \beta 1$-tetraspanin complexes (Sugiura and Berditchevski, 1999). Recent findings indicate that the PI3K/AKT pathway can play a critical role in anchorage-independent tumor cell survival and metastasis (Nakanishi et al, 2002). How CD63/ $\alpha 3 \beta 1$ complexes transduce signals upon ligation of $\alpha 3 \beta 1$ to $\mathrm{LN}-5$ to affect matrix proteolysis, cytoskeletal organization, and migration remains to be determined. LN-5 is consistently identified at invasive edges of both healing wounds and tumors, including colorectal cancer, where cells actively migrate (Sordat et al, 1998). The experimental evidence presented in this article strongly suggests that the CD63/ $\alpha 3 \beta 1$ association is involved in the complex process of tumor cell adhesion and invasive migration driven by integrin-LN-5 interaction.

\section{Materials and Methods}

\section{Cells, RNA Preparation, Antibodies, and Reagents Used in the Study}

E2 and C5 clones originally derived from the Lovo line were obtained from Dr. L. Remy (INSERM, U45, Lyon) and grown in Dulbecco's modified Eagle's medium (DMEM) medium (GibcoBRL, Rockville, Maryland) supplemented with $10 \%$ heat-inactivated fetal bovine serum (FBS) (GibcoBRL). Cells were scraped on ice and cytoplasmic RNA extraction was performed following standard procedures. PolyA + mRNA was extracted from total RNA using Dynabeads (Dynal, Oslo, Norway). Antibodies used in this study were P1B5 and CD49c (clone C3), which block the function of $\alpha 3$ integrin (Life Technologies, Gaithersburg, Maryland, and Immunotech, Westbrook, Maine) and nonblocking antibody M-KID2 (Chemicon, Temecula, California); the human antibody CD29 (clone Lia 1/2) against $\beta 1$ integrin (Immunotech); the antibodies AHN16.1 (clone 46-4-6) (Alexis, Bayport, Minnesota) and TS63 (Dr. E. Rubinstein, Paris, France), which recognize CD63 tetraspanin. Antibody BM165 against human LN-5 was a kind gift from Dr. P. Rousselle (IBCP, Lyon, France). The mouse IgG1 (MOPC-21) used as a mAb negative 


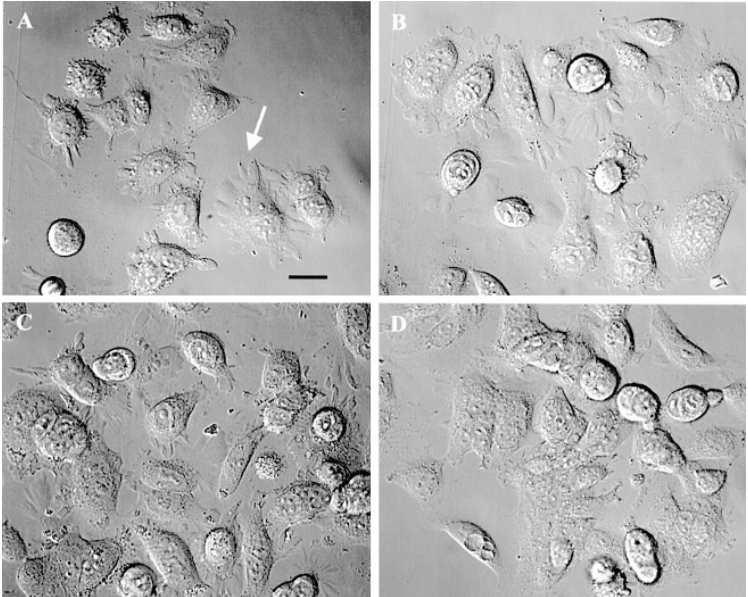

Figure 6.

Morphogenic responses of E2 cells to substrate-immobilized anti-CD63 tetraspanin AHN16.1 mAb. Over 50\% of E2 cells show numerous long cytoplasmic extensions (A, arrow) that are not affected by anti-LN-5 (B) or anti- $\alpha 3$ integrin chain $(C)$ antibodies. In contrast, mAb-induced protrusive activity is repressed by LY294002, an inhibitor of PI3K (D). Interference contrast microscopy. Bar $=10 \mu \mathrm{m}$.

control was from Sigma (St. Louis, Missouri). LY 294002 was from Calbiochem-Novobiochem Corp. (La Jolla, California).

\section{Expression Profiling by Quantitative Hybridization on Macroarrays}

cDNA macro arrays containing a total of 2208 cDNA clones from a normalized infant brain library spotted onto nylon membranes were prepared as previously described (Pietu et al, 1999). Complex cDNA probes were synthesized as previously described (Decraene et al, 1999) by reverse transcription of $500 \mathrm{ng}$ poly $(A)^{+}$ mRNA, and hybridization steps were performed on duplicate filters and repeated with novel probes ensuring that, for each clone/probe combination, four hybridization data points could be collected. Hybridization signals were captured and analyzed as described (Decraene et al, 1999). In order to compare gene expression in E2 versus C5 or C5 versus E2 mRNAs, a ratio was performed between the hybridization intensity values obtained in both conditions, and a ratio of 1.5 was taken into account to consider that a gene presents a differential expression.

\section{Northern Blot Analysis}

Total RNA was separated on denaturing agarose gels, transferred to Hybond-N+ membranes (Amersham Pharmacia Biotech) and hybridized to [alpha $\left.{ }^{33} \mathrm{P}\right] \mathrm{dATP}$ labeled probes derived from each cDNA clone by amplification by PCR. Filters were stripped, allowing hybridization with 18S rRNA probe. Scan analyses were performed with AIDA2.0 software (Raytest, Straubenhardt, Germany).

\section{Flow Cytometry}

E2 and C5 cells were detached using a nonenzymatic cell-dissociation solution (Sigma) and incubated with the anti- $\alpha 3$ integrin (P1B5), anti-CD63 tetraspanin (AHN16.1), or control antibodies for 30 minutes on ice, washed once with PBS, and incubated with FITCconjugated goat anti-mouse (Caltag, South San Francisco, California) immunoglobulin for 30 minutes on ice. Following two washes, cells were analyzed with a FACScan (Becton Dickinson, Mountain View, California).

\section{Immunostaining}

Dual immunostaining was performed using a three-step procedure. First, the mAb P1B5 $(5 \mu \mathrm{g} / \mathrm{ml})$ was applied to ethanol-ether-fixed-permeabilized PBS/BSA rehydrated cells that were then treated, following three washes, with a Cy3-conjugated goat anti-mouse lgG $(5 \mu \mathrm{g} / \mathrm{ml}$; Jackson Immunoresearch Laboratories, West Grove, Pennsylvania). Finally, cells were exposed to the FITC-labeled AHN16.1 mAb (10 $\mu \mathrm{g} / \mathrm{ml}$; Ancell Corporation, Bayport, Minnesota) and subsequently washed, mounted in Citifluor (Citifluor, Canterbury, United Kingdom), and analyzed using a Zeiss LS 510 confocal microscope. Crosstalk between the different channels was excluded by using a sequential scan inactivating the specific laser line (Zeiss multitracking mode).

\section{Cell Adhesion Assay}

Ninety-six-well tissue culture plates (Nunc, Naperville, Illinois) were coated overnight at $4^{\circ} \mathrm{C}$ with fibronectin (FN) (Roche Diagnostics), rat collagen type 1 (RTC), laminin-1 (LN-1) (LN-1, EHS-laminin both from Sigma), and human LN-5 (kindly provided by P. Rousselle, IBCP, Lyon). Cell adhesion assays were performed in triplicate as described previously. Briefly, either cells were incubated 1 hour with the respective antibody or not, washed with DMEM, and then incubated 30 minutes in DMEM containing $5 \mu \mathrm{M}$ calcein-AM (Molecular Probes, Eugene, Oregon). Labeled cells were then washed twice with DMEM containing $1 \%$ FBS. Then 5 $\times 10^{4}$ E2 and C5 cells were seeded and plates centrifuged 2 minutes at $100 \mathrm{rpm}$ and incubated 45 minutes at $37^{\circ} \mathrm{C}$. Total cell fluorescence was measured, then wells were washed twice with DMEM $1 \%$ FBS and results expressed as the percent of total fluorescent cells that had adhered.

\section{Cell Invasion and Wound Closure Assays}

Subconfluent cultures of E2 and C5 cells were detached and passed through a 25-G needle. Polycarbonate membranes (8.0- $\mu \mathrm{m}$ pore size) were precoated with 100 $\mu \mathrm{g} / \mathrm{ml}$ Matrigel (Becton-Dickinson) and inserted in a 12-well Boyden-type migration chamber (Neuroprobe). Ten percent FBS DMEM was used as a chemoattractant in the lower compartment. The chemoinvasion assay was performed in the presence of antibodies added either to the upper compartment or admixed to the Matrigel filter coat. Results are expressed as the percent of total cells that had penetrated and migrated through the Matrigel. Wound closure assays were performed in four-chamber Lab-Tek II glass slides (Nunc) with/without anti-CD63 AHN16.1 antibody coating. E2 or C5 cells $\left(5.10^{4} / 400-\mu\right.$ l chamber) were seeded and cultured until 
subconfluent. Then cell layers were wounded with a plastic tip (10- $\mu$ l size) and washed three times with $10 \%$ FBS DMEM. Antibodies or their combinations were added and cells were incubated for 17 and 24 hours at $37^{\circ} \mathrm{C}$. Photographs of identical locations within each wound were taken at 0,17 , and 24 hours. Cell migration was determined by multiple measurements of the distance between the edges of individual wounds as compared with the 0 time point.

\section{Acknowledgements}

We would like to thank Dr. Lionel Rémy for providing the E2/C5 clones, Dr. Eric Rubinstein for the kind gift of anti-CD63 antibodies, and Dr. Patricia Rousselle for helpful discussions. We thank Dr. Nathalie Garin (Microscopy Imaging Morphology Service, ISREC) for help in confocal microscopy.

\section{References}

Berditchevski F (2001). Complexes of tetraspanins with integrins: More than meets the eye. J Cell Sci 114:4143-4151.

Berditchevski F, Bazzoni G, and Hemler ME (1995). Specific association of CD63 with the VLA-3 and VLA-6 integrins. J Biol Chem 270:17784-17790.

Berditchevski F and Odintsova E (1999). Characterization of integrin-tetraspanin adhesion complexes: Role of tetraspanins in integrin signaling. J Cell Biol 146:477-492.

Boucheix C, Huynh Tien Duc G, Jasmin C, and Rubinstein E (2001). Tetraspanins and malignancy. Exp Rev Mol Med. 31 January. Available at: http://www-ermm.cbcu.cam.ac.uk/ 01002381h.htm

Boucheix C and Rubinstein E (2001). Tetraspanins. Cell Mol Life Sci 58:1189-1205.

Decraene C, Reguigne-Arnould I, Auffray C, and Pietu G (1999). Reverse transcription in the presence of dideoxynucleotides to increase the sensitivity of expression monitoring with cDNA arrays. Biotechniques 27:962-966.

Hemler ME (2001). Specific tetraspanin functions. J Cell Biol 155:1103-1107.

Hemler ME, Mannion BA, and Berditchevski F (1996). Association of TM4SF proteins with integrins: Relevance to cancer. Biochim Biophys Acta 1287:67-71.

Hintermann E, Bilban M, Sharabi A, and Quaranta V (2001). Inhibitory role of alpha 6 beta 4-associated erbB-2 and phosphoinositide 3-kinase in keratinocyte haptotactic migration dependent on alpha 3 beta 1 integrin. J Cell Biol 153:465-478.

Hotta H, Hara I, Miyamoto H, and Homma M (1991). Overexpression of the human melanoma-associated antigen ME491 partially suppresses in vivo malignant phenotypes of $\mathrm{H}$-ras-transformed NIH3T3 cells in athymic nude mice. Melanoma Res 1:125-132.

Hotta H, Ross AH, Huebner K, Isobe M, Wendeborn S, Chao MV, Ricciardi RP, Tsujimoto Y, Croce CM, and Koprowski H (1988). Molecular cloning and characterization of an antigen associated with early stages of melanoma tumor progression. Cancer Res 48:2955-2962.
Nakanishi K, Sakamoto M, Yasuda J, Takamura M, Fujita N, Tsuruo T, Todo S, and Hirohashi S (2002). Critical involvement of the phosphatidylinositol 3-kinase/Akt pathway in anchorageindependent growth and hematogeneous intrahepatic metastasis of liver cancer. Cancer Res 62:2971-2975.

Pietu G, Mariage-Samson R, Fayein NA, Matingou C, Eveno E, Houlgatte R, Decraene C, Vandenbrouck Y, Tahi F, Devignes MD, Wirkner U, Ansorge W, Cox D, Nagase T, Nomura N, and Auffray C (1999). The Genexpress IMAGE knowledge base of the human brain transcriptome: A prototype integrated resource for functional and computational genomics. Genome Res 9:195-209.

Radford KJ, Mallesch J, and Hersey P (1995). Suppression of human melanoma cell growth and metastasis by the melanomaassociated antigen CD63 (ME491). Int J Cancer 62:631-635.

Radford KJ, Thorne RF, and Hersey P (1997). Regulation of tumor cell motility and migration by CD63 in a human melanoma cell line. J Immunol 158:3353-3358.

Remy L, Lissitzky JC, Daemi N, Jacquier MF, Bailly M, Martin PM, Bignon C, and Dore JF (1992). Laminin expression by two clones isolated from the colon carcinoma cell line LoVo that differ in metastatic potential and basement-membrane organization. Int J Cancer 51:204-212.

Ross DT, Scherf U, Eisen MB, Perou CM, Rees C, Spellman $P$, lyer V, Jeffrey SS, Van de Rijn M, Waltham M, Pergamenschikov A, Lee JC, Lashkari D, Shalon D, Myers TG, Weinstein JN, Botstein D, and Brown PO (2000). Systematic variation in gene expression patterns in human cancer cell lines. Nat Genet 24:227-235.

Schmidt A and Hall MN (1998). Signaling to the actin cytoskeleton. Annu Rev Cell Dev Biol 14:305-338.

Sordat I, Bosman FT, Dorta G, Rousselle P, Aberdam D, Blum AL, and Sordat B (1998). Differential expression of laminin- 5 subunits and integrin receptors in human colorectal neoplasia. J Pathol 185:44-52.

Sorlie T, Perou CM, Tibshirani R, Aas T, Geisler S, Johnsen H, Hastie $T$, Eisen MB, van de Rijn M, Jeffrey SS, Thorsen T, Quist H, Matese JC, Brown PO, Botstein D, Eystein Lonning $P$, and Borresen-Dale AL (2001). Gene expression patterns of breast carcinomas distinguish tumor subclasses with clinical implications. Proc Natl Acad Sci USA 98:10869-10874.

Stipp CS and Hemler ME (2000). Transmembrane-4superfamily proteins CD151 and CD81 associate with alpha 3 beta 1 integrin, and selectively contribute to alpha 3 beta 1-dependent neurite outgrowth. J Cell Sci 113:1871-1882.

Su Al, Welsh JB, Sapinoso LM, Kern SG, Dimitrov P, Lapp H, Schultz PG, Powell SM, Moskaluk CA, Frierson HF Jr, and Hampton GM (2001). Molecular classification of human carcinomas by use of gene expression signatures. Cancer Res 61:7388-7393.

Sugiura $T$ and Berditchevski $F$ (1999). Function of alpha3beta1-tetraspanin protein complexes in tumor cell invasion. Evidence for the role of the complexes in production of matrix metalloproteinase 2 (MMP-2). J Cell Biol 146:1375-1389.

Testa JR and Bellacosa A (2001). AKT plays a central role in tumorigenesis. Proc Natl Acad Sci USA 98:10983-10985.

Zhang L, Zhou W, Velculescu VE, Kern SE, Hruban RH, Hamilton SR, Vogelstein B, and Kinzler KW (1997). Gene expression profiles in normal and cancer cells. Science 276:1268-1272. 